\title{
Avaliação comparativa dos sintomas da síndrome de burnout em professores de escolas públicas e privadas
}

\author{
ALBERTO ABRANTES ESTEVES-FERREIRA \\ Universidade Federal de Viçosa, \\ Viçosa, MG, Brasil \\ DOUGLAS ELIAS SANTOS \\ Universidade Federal de Viçosa, \\ Viçosa, MG, Brasil \\ RAFAEL GUSTAVO RIGOLON \\ Universidade Federal de Viçosa, \\ Viçosa, MG, Brasil
}

RESUMO

Atualmente, observa-se em parte dos docentes em exercício um sentimento de desmotivação em relação à sua profissão. Frequente entre os educadores, a síndrome de burnout caracteriza-se pela perda do sentimento de realização no trabalho, com produtividade diminuída. Nesse contexto, objetivou-se avaliar a presença dos sintomas dessa síndrome entre profissionais do ensino público e privado no município de Viçosa/MG, de modo que se identificasse qual grupo estaria mais predisposto a desenvolvê-la. Os dados obtidos não permitem quantificar se os docentes apresentam a síndrome de burnout, mas é possível inferir que docentes de instituições públicas apresentam características que os tornam mais propensos a manifestar tal síndrome, quando comparados aos profissionais que atuam no ensino privado.

síndrome de burnout; ensino básico; satisfação profissional. 


\title{
COMPARATIVE EVALUATION OF THE SYMPTOMS OF BURNOUT SYNDROME OF TEACHERS IN PUBLIC AND PRIVATE SCHOOLS
}

\begin{abstract}
Currently, there are some practicing teachers who are unmotivated. Frequent among educators, the burnout syndrome is characterized by a loss of the sense of accomplishment at work and decreased productivity. In this context, the objective was to assess the presence of symptoms of burnout syndrome among professionals in public and private schools in $\mathrm{Viçosa/MG}$, and to identify which group was more prone to develop it. The data does not quantify whether teachers have burnout syndrome or not, but it is possible to infer that teachers of public institutions have characteristics that make them more likely to manifest the syndrome, when compared to teachers in private education.
\end{abstract}

KEYWORDS

burnout syndrome; basic education; professional satisfaction.

\section{EVALUACIÓN COMPARATIVA DE LOS SÍNTOMAS DEL SÍNDROME DE BURNOUT EN PROFESORES DE ESCUELAS PÚBLICAS Y PRIVADAS}

\section{RESUMEN}

En la actualidad, se observa en parte de los docentes en ejercicio, una sensación de desmotivación en relación a su profesión. Frecuente entre los educadores, el síndrome de burnout se caracteriza por la pérdida de sentimiento de realización en el trabajo, con productividad disminuida. En este contexto, el objetivo fue evaluar la presencia de síntomas de síndrome de burnout entre los profesionales de las escuelas públicas y privadas de la ciudad de Viços/MG, con el fin de idenetificar qué grupo estaría más propenso a desarrollarla. Los datos obtenidos no permiten cuantificar si los docentes presentan síntomas del síndrome de burnout, pero sí permiten inferir que los profesores de las instituciones públicas poseen características que los vuelven más propensos a manifestar el síndrome, en comparación con los profesionales de la educación privada. 


\section{INTRODUÇÃO}

Segundo Fígoli (2006), apesar de o número de pessoas sem acesso à educação formal no Brasil ter diminuído, o atual cenário educacional brasileiro é preocupante. Relatos de descontentamento profissional, bem como decepção, estão ficando cada vez mais rotineiros no panorama geral dos professores (Ramos, 2008). Pesquisas revelam altos índices de abandono do cargo, além de um grande número de casos de afastamento temporário, tendo como causas o baixo salário, as péssimas condições de trabalho, a perda de identidade e as inúmeras doenças ocupacionais (Lapo, 1999).

De acordo com Gatti (1996), a questão salarial não se apresenta como um fator isolado de insatisfação dos docentes. A ausência de uma remuneração coerente leva esses profissionais a acumularem cargos, aumentando de maneira demasiada sua jornada de trabalho. Esse aumento acarreta sérios problemas na qualidade das aulas ministradas, pois, no turno em que o professor poderia estar preparando suas aulas, ele se encontra lecionando em outra(s) escola(s) para complementar seu orçamento familiar. Como também a jornada excessiva de trabalho leva a vários problemas de saúde, sendo comum nesses profissionais doenças de caráter respiratório e mental.

Segundo os docentes, os principais fatores que levam ao desenvolvimento do estresse são as preocupações com o desenvolvimento acadêmico, a insatisfação com o salário, condições de trabalho adversas, indisciplina dos alunos, falta de participação dos pais e a desvalorização da carreira do magistério, sem possibilidades de progredir (Amado, 2000).

De uma maneira mais avançada e peculiar, há ainda o quadro de sintomas relacionados à síndrome de burnout. Trata-se de uma síndrome em que o prazer e realização pelo trabalho diminuem com o passar do tempo, como decorrência direta da relação entre o ambiente de trabalho e a resposta psíquica-comportamental do indivíduo. $\mathrm{O}$ trabalhador arma inconscientemente uma retirada psicológica, um modo de abandonar o trabalho, apesar de continuar no posto (Codo, 1999). Nesse caso, isso se torna prejudicial tanto para o professor quanto para os alunos.

\section{BURNOUT EM PROFESSORES}

A síndrome de burnout é mais uma doença que se tem mostrado significativa e sua principal causa parece ser o estresse prolongado (Reinhold, 2001). O burnout refere-se a uma reação de estresse crônico em profissionais cujas atividades exigem um alto grau de contato com pessoas. Ele caracteriza-se por três componentes: exaustão emocional e/ou física; perda do sentimento de realização no trabalho, com produtividade diminuída; despersonalização extrema (Codo, 1999).

Cury (2001 apud Pinotti, 2005/2006, p. 212), em pesquisa realizada com professores da rede pública de ensino, mostrou que $92 \%$ dos professores do país apresentavam sinais de distúrbios causados pelo estresse, como dores de cabeça, ansiedade, transtornos do sono, cansaço excessivo, déficit de memória e concentração. De acordo com Amado (2000), os professores chegam a apresentar doenças como transtornos neuróticos, depressão, hemorroida, doenças do sistema digestório, amigdalite e infecção das vias respiratórias superiores.

Diversos trabalhos apontam que ser professor é uma das profissões mais estressantes na atualidade (Carlotto, 2002; Moreno-Jimenez et al. 2002; Silva et al. 
2008). A Confederação Nacional dos Trabalhadores em Educação (CNTE) realizou uma pesquisa, entre os anos de 1996 a 1998, na qual a entidade entrevistou 52 mil professores de todos os estados. A pesquisa destaca que $50 \%$ dos entrevistados apresentavam a chamada síndrome de burnout (Pinotti, 2005/2006). Segundo Levy (2006), a sobrecarga e a extensa jornada de trabalho geram desconforto entre os professores, propiciando o aparecimento da síndrome de burnout, principalmente em profissionais que trabalhem mais de sessenta horas semanais.

Sem um preparo prévio, os professores são expostos a uma pressão, exercida especialmente pelas novas tecnologias, sendo necessária uma revisão em sua metodologia de ensino. Isso conduz a um "novo" processo de formação de professores, os quais, além de possuírem conhecimentos técnicos, devem ser criativos e ter liderança, possuir especialização contínua, saber superar quaisquer obstáculos e ter capacidade de autodesenvolvimento (Kullok, 2000 apud Kullok, 2010, p. 47). Afetados por esses problemas, a eles somados os sucessos e fracassos dos alunos e suas próprias exigências, os professores tornam-se esgotados e mais propícios ao burnout (Pinotti, 2005/2006).

Segundo Naujorks (2002), as atividades pedagógicas permeadas por circunstâncias desfavoráveis forçam a uma reorganização e improvisação no trabalho planejado, distorcem o conteúdo das atividades e tornam o trabalho descaracterizado em relação às expectativas, gerando um processo de permanente insatisfação e induzindo a sentimentos de indignidade, fracasso, impotência, culpa e desejo de desistir.

Ao indagar se os professores haviam pensado em desistir da profissão, Caldas (2007) constatou que alguns deles se encontravam dispostos a abandonar a docência, enquanto outros afirmaram que nunca haviam pensado em desistir, mas que muitas vezes desanimaram. Entre os motivos assinalados pelos professores como influenciadores do sentimento de desistência do magistério, destacaram-se a desvalorização da profissão, as más condições de trabalho, a carga mental do trabalho, os baixos salários, as relações sociais na escola e o aumento da violência.

Folle e Nascimento (2009) concluem que o desejo de abandono da docência advém das frustrações vivenciadas pelos professores no dia a dia de sua profissão, principalmente com as relações estabelecidas e as condições de trabalho oferecidas. Contudo, o afastamento da profissão docente não tem se concretizado, devido à estabilidade profissional e à segurança financeira proporcionada por essa carreira. $\mathrm{O}$ autor também destaca que os professores acreditam ter consolidado sua carreira ao longo dos anos de atuação profissional. Além disso, por não terem desistido do magistério público, estão aguardando o direito concedido por lei para se afastar definitivamente do ambiente de trabalho e gozar dos benefícios conferidos pela aposentadoria. Vê-se, então, que a aposentadoria também pode ser um fator que influencia a não desistência desses docentes.

Nas últimas décadas, muitas pesquisas realizadas no exterior têm abordado o estresse ocupacional de professores, alertando para a seriedade do problema e suas implicações no sistema educacional. No Brasil, entretanto, a produção científica ainda é pequena e bastante recente (Pinotti, 2005/2006). Para colaborar com a pesquisa nacional nessa área, os objetivos deste trabalho foram analisar o nível de satisfação desses professores em relação à profissão e o que os leva a permanecerem no cargo, conhecer o número de cargos que possuem ou se exercem outra(s) atividade(s) remunerada(s), averiguar a presença de doenças decorrentes da profissão 
do magistério e identificar sintomas que caracterizem a presença da síndrome de burnout nos profissionais do município de Viçosa/MG.

\section{PROCEDIMENTOS DE INVESTIGAÇÃO}

Para avaliar a presença dos sintomas da síndrome de burnout em professores, foi elaborado um questionário composto de questões abertas (discursivas).

Os questionários foram distribuídos em instituições públicas e privadas de ensino básico do município de Viçosa, sendo aplicados em um total de dezoito escolas, separadas em municipais, estaduais e particulares (seis de cada). Para responder os questionários, foram escolhidos, em cada uma das escolas, de maneira aleatória, dez professores atuantes que lecionam entre o primeiro e o nono ano do ensino básico, obtendo no final um total de 180 questionários entregues.

As questões elaboradas tratavam da formação acadêmica dos docentes, dos principais motivos que os levaram a escolher a profissão, do porquê da sua permanência, do grau de satisfação dos profissionais, do número de cargos em que atuam ou se exercem outra(s) atividade(s) remunerada(s), da presença de alguma(s) enfermidade(s), das condições de trabalho e das perspectivas em relação à educação.

Para a análise dos resultados, foram utilizados os métodos de categorização e análise de conteúdo (Bardin, 1977; Rocha; Deusdará, 2005). O método de análise de conteúdo permitiu não só compreender a mensagem transmitida pelo docente ao redigir sua resposta, mas também, interpretar seu sentido e o contexto das palavras empregadas. Esse método propiciou obter resultados mais coesos e confiáveis, que nos levaram a poder identificar melhor a presença de sintomas que caracterizem a síndrome de burnout nesses profissionais. Os recortes das respostas aqui apresentados, para exemplificação, foram transcritos literalmente. ${ }^{1}$

\section{RESULTADOS E DISCUSSÃO}

Entre os 180 questionários distribuídos nas três redes de ensino, 71 foram respondidos pelos professores, correspondendo a um percentual de apenas 39,44\% de participação. A greve dos professores do ensino público, ocorrida durante alguns meses de 2011, a dificuldade em conseguir a cooperação de algumas escolas da rede particular e o fato de muitos professores levarem os questionários para serem respondidos em casa, mas não retornarem com os mesmos, foram alguns dos fatores que impossibilitaram a obtenção de um maior número de questionários.

Essa última observação, porém, pode ser justificada pelas jornadas de trabalho às quais alguns dos professores têm que se submeter para obter uma remuneração adequada, pois $45,09 \%$ e $13,72 \%$ dos profissionais entrevistados trabalham em dois e três turnos, respectivamente. Meleiro (2000) relata que devido a essa extensa jornada de trabalho boa parte dos compromissos são levados para casa e, assim, a competência do professor é desafiada para encontrar uma forma de resolver ou, pelo

1 Os questionários foram respondidos anonimamente, por isso não forneceremos nenhum tipo de identificação para os trechos citados. 
menos, minimizar os problemas. Carlotto (2005) destaca que esse ritmo acelerado de trabalho ainda se intensifica no caso da mulher, a qual exerce dupla ou tripla jornada de trabalho, acumulando trabalho remunerado com afazeres domésticos, que continuam sendo entendidos como de sua responsabilidade.

Os resultados dessas pesquisas corroboram com os da presente pesquisa, pois $84,5 \%$ dos profissionais eram do sexo feminino, $63,38 \%$ eram casados, $66,19 \%$ tinham filhos e $21,56 \%$ exerciam outra atividade remunerada além da docência. Maslach, Schaufeli e Leiter (2001) relatam que não há unanimidade quanto à maior susceptibilidade do burnout em homens ou mulheres, sendo comum nas mulheres quadros de exaustão emocional e nos homens desumanização. Quanto ao casamento, os autores geralmente atribuem a menor propensão ao burnout em profissionais que possuem um companheiro estável, porém a qualidade do relacionamento se mostra mais importante do que apenas ter um companheiro. Em relação à presença de filhos, há controvérsias sobre os benefícios que esse fator pode ou não vir a causar (Sampson, 1990 apud Benevides-Pereira, 2002).

Dos professores entrevistados em todo o município de Viçosa, 54,93\% possuem mais de 40 anos de idade e 53,52\% exercem a profissão há mais de dez anos. De acordo com Levy (2006), os professores de mais idade e experiência são menos vulneráveis ao burnout, pois são mais bem capacitados para administrar situações de sala de aula, por utilizarem recursos técnicos e habilidade profissionais adquiridas ao longo do tempo.

Quanto à realização profissional, 60\% dos docentes das três redes de ensino do município de Viçosa afirmaram que se sentem realizados. Os professores que lecionam em escolas estaduais mostraram-se mais insatisfeitos, contrapondo com o quadro encontrado entre os docentes da rede particular. De acordo com as respostas obtidas, o prazer pelo trabalho mostrou ser o principal fator que leva esses profissionais a sentirem-se realizados profissionalmente. Porém, principalmente entre os professores do ensino público, a questão salarial e a jornada de trabalho excessiva se destacaram como os principais desencadeadores de insatisfação (Tabela 1).

Esses dados corroboram os de Gatti (1996) e Levy (2006), que destacam a questão salarial como central, por acarretar a necessidade do aumento da jornada de trabalho, já que para a maioria dos professores o salário é fundamental para a manutenção da família. No entanto, esse aumento na carga de trabalho acarreta sérios problemas na qualidade das aulas ministradas, como também gera desconforto entre os professores, propiciando o aparecimento da síndrome de burnout, principalmente em profissionais que trabalham mais de sessenta horas semanais.

Em respostas de professores das escolas públicas, é comum encontrar o dilema entre o prazer pela profissão e a realização profissional:

"Não. Gosto muito do que faço. Dentro de sala sinto-me realizada, é uma terapia, mas a jornada tripla de trabalho, muitas atividades a serem realizadas no final de semana, tudo isto faz com que eu não me realize como ser humano, cuido pouco de mim". 
Tabela 1 - Categorias citadas pelos professores com relação à realização profissional

\begin{tabular}{|c|c|c|c|c|c|c|c|}
\hline \multirow[t]{2}{*}{ Afirmativa } & \multirow[t]{2}{*}{ Categorias } & \multicolumn{2}{|c|}{$\begin{array}{c}\text { Escolas } \\
\text { Estaduais }\end{array}$} & \multicolumn{2}{|c|}{$\begin{array}{c}\text { Escolas } \\
\text { Municipais }\end{array}$} & \multicolumn{2}{|c|}{$\begin{array}{c}\text { Escolas } \\
\text { Particulares }\end{array}$} \\
\hline & & $\mathrm{N}$. & $\%$ & N. & $\%$ & N. & $\%$ \\
\hline \multirow{6}{*}{ Sim } & Ausência de justificativa & 2 & 8,00 & 1 & 3,84 & 7 & 35,00 \\
\hline & Retorno por parte dos alunos & 1 & 4,00 & 1 & 3,84 & 0 & 0,00 \\
\hline & Valorização pessoal & 0 & 0,00 & 3 & 11,54 & 2 & 10,00 \\
\hline & Valorização profissional & 1 & 4,00 & 4 & 15,38 & 2 & 10,00 \\
\hline & Prazer pelo trabalho & 9 & 36,00 & 8 & 30,76 & 4 & 20,00 \\
\hline & Total & 13 & 52,00 & 17 & 65,36 & 15 & 75,00 \\
\hline \multirow{8}{*}{ Não } & Ausência de realização pessoal & 0 & 0,00 & 0 & 0,00 & 1 & 5,00 \\
\hline & Baixo salário & 6 & 24,00 & 4 & 15,38 & 2 & 10,00 \\
\hline & Desinteresse dos alunos & 1 & 4,00 & 0 & 0,00 & 1 & 5,00 \\
\hline & Desvalorização profissional & 2 & 8,00 & 2 & 7,69 & 0 & 0,00 \\
\hline & Infraestrutura inadequada & 2 & 8,00 & 0 & 0,00 & 0 & 0,00 \\
\hline & Jornada de trabalho excessiva & 2 & 8,00 & 2 & 7,69 & 0 & 0,00 \\
\hline & Falta de tempo para realizar outras atividades & 0 & 0,00 & 2 & 7,69 & 1 & 5,00 \\
\hline & Total & 13 & 52,00 & 10 & 38,45 & 5 & 25,00 \\
\hline \multirow{3}{*}{ Não sei } & Ausência de reconhecimento & 1 & 4,00 & 1 & 3,84 & 0 & 0,00 \\
\hline & Desvalorização profissional & 0 & 0,00 & 0 & 0,00 & 1 & 5,00 \\
\hline & Total & 1 & 4,00 & 1 & 3,84 & 1 & 5,00 \\
\hline
\end{tabular}

Fonte: Banco de dados da pesquisa.

Elaboração dos autores.

Nesse contexto em que alguns professores declaram-se realizados, questionamos se eles sentiam-se recompensados pela sua dedicação na sala de aula. Os resultados obtidos nas três redes de ensino mostraram-se bastante similares e aproximadamente $52 \%$ dos professores entrevistados afirmaram que sim, citando o prazer em exercer a profissão e a satisfação profissional como os principais motivos. Em contrapartida, aproximadamente $34 \%$ dos profissionais, principalmente do ensino público, não se veem recompensados pelos seus esforços, citando como fatores principalmente a insatisfação profissional, o baixo salário e o desinteresse dos alunos (Tabela 2).

Os dados encontrados nesta pesquisa corroboram os de Garcia (1990) e Benevides-Pereira (2002), demonstrando que a ausência de retorno quanto ao serviço realizado, tanto por parte da pessoa que deles usufrui como dos colegas e superiores, também tem sido apontada como elemento propiciador de incremento do burnout. Para os autores, o feedback negativo tem grande importância na predisposição da síndrome, em especial na dimensão de despersonalização. Esses fatores foram identificados em relatos dos docentes do ensino público entrevistados nesta pesquisa: "Não sei. Em partes. O trabalho é reconhecido na escola e, assim, recompensador. Em relação aos alunos, ou à resposta, feedback, nem sempre nos sentimos recompensados; financeiramente a desvalorização é geral”. Em outro relato é possível identificar o descontentamento dos professores comprometidos, quando não são recompensados por seus esforços: "Não. A cobrança em uma escola particular, não 


\section{Tabela 2 - Percentual de docentes que se sentem recompensados ou não por seus esforços}

\begin{tabular}{|c|c|c|c|c|c|c|c|}
\hline \multirow[t]{2}{*}{ Afirmativa } & \multirow[t]{2}{*}{ Categorias } & \multicolumn{2}{|c|}{$\begin{array}{c}\text { Escolas } \\
\text { Estaduais }\end{array}$} & \multicolumn{2}{|c|}{$\begin{array}{c}\text { Escolas } \\
\text { Municipais }\end{array}$} & \multicolumn{2}{|c|}{$\begin{array}{c}\text { Escolas } \\
\text { Particulares }\end{array}$} \\
\hline & & N. & $\%$ & N. & $\%$ & $\mathrm{~N}$. & $\%$ \\
\hline \multirow{5}{*}{ Sim } & Ausência de justificativa & 4 & 16,00 & 2 & 8,00 & 4 & 20,00 \\
\hline & Faz o que gosta & 1 & 4,00 & 3 & 12,00 & 0 & 0,00 \\
\hline & Realização pessoal & 1 & 4,00 & 1 & 4,00 & 0 & 0,00 \\
\hline & Realização profissional & 8 & 32,00 & 8 & 32,00 & 5 & 25,00 \\
\hline & Total & 14 & 56,00 & 14 & 56,00 & 9 & 45,00 \\
\hline \multirow{6}{*}{ Não } & Ausência de justificativa & 1 & 4,00 & 2 & 8,00 & 2 & 10,00 \\
\hline & Baixo salário & 2 & 8,00 & 3 & 12,00 & 3 & 15,00 \\
\hline & Desinteresse dos alunos & 2 & 8,00 & 0 & 0,00 & 0 & 0,00 \\
\hline & Desvalorização profissional & 0 & 0,00 & 0 & 0,00 & 0 & 0,00 \\
\hline & Insatisfação profissional & 6 & 24,00 & 2 & 8,00 & 1 & 5,00 \\
\hline & Total & 11 & 44,00 & 7 & 28,00 & 6 & 30,00 \\
\hline \multirow{3}{*}{ Não sei } & Ausência de justificativa & 0 & 0,00 & 0 & 0,00 & 2 & 10,00 \\
\hline & De acordo com os resultados & 0 & 0,00 & 4 & 16,00 & 3 & 15,00 \\
\hline & Total & $\mathbf{0}$ & 0,00 & 4 & 16,00 & 5 & 15,00 \\
\hline
\end{tabular}

Fonte: Banco de dados da pesquisa.

Elaboração dos autores.

só da escola mas da família, é muito grande e muitas vezes os esforços do professor não são reconhecidos, principalmente pela família, que sempre tem algo a reclamar".

Mediante essa situação, perguntou-se aos docentes sobre seu entusiasmo em relação à sala de aula. Aproximadamente $55 \%$ dos entrevistados relatam ter mantido ou até mesmo aumentado seu entusiasmo após anos de dedicação à docência, sendo os valores obtidos nas redes públicas e privadas muito semelhantes. Fatores como o gosto pela profissão que exercem, a experiência profissional edificada ao longo dos anos, o comprometimento e os resultados satisfatórios são justificativas para essa afirmativa. Outros $36 \%$ dos docentes, em grande parte da rede pública, afirmaram sentir uma redução do entusiasmo. Fatores como o desinteresse dos alunos, as condições de trabalho inadequadas e o sentimento de desvalorização foram citados como desencadeadores desse processo. Apenas 8,33\% não souberam responder a esse questionamento em virtude do pouco tempo de carreira (Tabela 3).

Para Maslach Schaufeli e Leiter (2001), a queda no entusiasmo é uma das características do sentimento de exaustão emocional presente em profissionais com burnout, como também a falta ou carência de energia e um sentimento de esgotamento de recursos.

Em um dos relatos obtidos pelos docentes entrevistados na presente pesquisa, é possível identificar o baixo entusiasmo com o ambiente de trabalho e os alunos: "A insatisfação com as condições de trabalho, os absurdos praticados nas relações [...], o desinteresse e desrespeito dos alunos, a alienação da categoria [...]”.

Os dados obtidos nesta pesquisa também confirmam os de Carlotto (2002), relatando que a perda de entusiasmo e criatividade devido à exaustão emocional 
Tabela 3 - Opinião dos profissionais em relação à manutenção do seu entusiasmo

\begin{tabular}{|c|c|c|c|c|c|c|c|}
\hline \multirow[t]{2}{*}{ Afirmativa } & \multirow[t]{2}{*}{ Categorias } & \multicolumn{2}{|c|}{$\begin{array}{c}\text { Escolas } \\
\text { Estaduais }\end{array}$} & \multicolumn{2}{|c|}{$\begin{array}{c}\text { Escolas } \\
\text { Municipais }\end{array}$} & \multicolumn{2}{|c|}{$\begin{array}{c}\text { Escolas } \\
\text { Particulares }\end{array}$} \\
\hline & & N. & $\%$ & N. & $\%$ & $\mathrm{~N}$. & $\%$ \\
\hline \multirow{9}{*}{ Sim } & Aprender com as dificuldades & 3 & 12,00 & 0 & 0,00 & 1 & 5,00 \\
\hline & Ausência de justificativa & 2 & 8,00 & 0 & 0,00 & 4 & 20,00 \\
\hline & Comprometimento & 1 & 4,00 & 3 & 12,00 & 1 & 5,00 \\
\hline & Experiência & 1 & 4,00 & 4 & 16,00 & 2 & 10,00 \\
\hline & Gosta do que faz & 6 & 24,00 & 5 & 20,00 & 1 & 5,00 \\
\hline & Início de carreira & 0 & 0,00 & 0 & 0,00 & 2 & 10,00 \\
\hline & Mais recursos disponíveis & 0 & 0,00 & 1 & 4,00 & 0 & 0,00 \\
\hline & Resultados satisfatórios & 1 & 4,00 & 2 & 8,00 & 0 & 0,00 \\
\hline & Total & 14 & 56,00 & 15 & 60,00 & 11 & 55,00 \\
\hline \multirow{6}{*}{ Não } & Baixo salário & 2 & 8,00 & 2 & 8,00 & 0 & 0,00 \\
\hline & Condições de trabalho inadequadas & 2 & 8,00 & 2 & 8,00 & 2 & 10,00 \\
\hline & Desinteresse e desrespeito & 7 & 28,00 & 2 & 8,00 & 2 & 10,00 \\
\hline & Desvalorização & 1 & 4,00 & 0 & 0,00 & 3 & 15,00 \\
\hline & Falta de entusiasmo & 0 & 0,00 & 1 & 4,00 & 0 & 0,00 \\
\hline & Total & 12 & 48,00 & 7 & 28,00 & 7 & 35,00 \\
\hline \multirow{5}{*}{ Não sei } & Ausência de justificativa & 0 & 0,00 & 0 & 0,00 & 2 & 10,00 \\
\hline & Desinteresse dos alunos & 0 & 0,00 & 1 & 4,00 & 0 & 0,00 \\
\hline & Falta de reconhecimento & 0 & 0,00 & 2 & 8,00 & 0 & 0,00 \\
\hline & Início de carreira & 1 & 4,00 & 0 & 0,00 & 0 & 0,00 \\
\hline & Total & 1 & 4,00 & 3 & 12,00 & 2 & 10,00 \\
\hline
\end{tabular}

Fonte: Banco de dados da pesquisa.

Elaboração dos autores.

acarreta prejuízos no planejamento de aula, tornando-o menos frequente e cuidadoso, queda na simpatia pelos alunos e baixo otimismo quanto à avaliação de seu futuro. Entretanto, mesmo que não se sintam realizados profissionalmente, muitos docentes entrevistados nessa pesquisa acabam por permanecer no cargo.

Questionados se desejavam se aposentar, caso fosse possível, apenas 20\% dos docentes da rede privada e aproximadamente $41 \%$ dos profissionais da rede pública apresentam vontade de se aposentar (Tabela 4).

Esses dados corroboram os de Lengert (2005). O autor destaca que, apesar do contexto negativo, a maioria dos professores não abandona definitivamente sua profissão, indicando como razões para a permanência o gosto pelo ensino e a expectativa de um reconhecimento que não conseguiria em sua nova função. Em declarações dos professores do ensino público do município de Viçosa, pode-se confirmar essa ideia: "Não. Apesar de todos os fatores que contribuem para desistir, acredito que ainda posso contribuir com a educação dos meus alunos".

Entre os professores que manifestaram anseio em se aposentar, essa escolha se mostrou maior na rede pública, sendo a insatisfação profissional e a pretensão em ter mais tempo para descansar e se dedicar à família os principais motivos para tomar essa decisão: "Sim. Para eu poder me dedicar mais à minha saúde e à criação/educação 


\section{Quadro 4 - Respostas dadas por professores em relação à vontade de se aposentar}

\begin{tabular}{|c|c|c|c|c|c|c|}
\hline \multirow[t]{2}{*}{ Afirmativa } & \multicolumn{2}{|c|}{$\begin{array}{l}\text { Escolas } \\
\text { Estaduais }\end{array}$} & \multicolumn{2}{|c|}{$\begin{array}{l}\text { Escolas } \\
\text { Municipais }\end{array}$} & \multicolumn{2}{|c|}{$\begin{array}{c}\text { Escolas } \\
\text { Particulares }\end{array}$} \\
\hline & $\mathrm{N}$. & $\%$ & N. & $\%$ & N. & $\%$ \\
\hline im & 10 & 40,00 & 11 & 42,31 & 4 & 20,00 \\
\hline Não & 15 & 60,00 & 15 & 57,69 & 16 & 80,00 \\
\hline Total & 25 & 100,00 & 26 & 100,00 & 20 & 100,00 \\
\hline
\end{tabular}

Fonte: Banco de dados da pesquisa.

Elaboração dos autores.

dos meus filhos". Entretanto, para os profissionais do ensino público, o afastamento definitivo da profissão docente não tem se concretizado devido à estabilidade profissional proporcionada por essa carreira, mesmo em um cenário de insatisfação salarial: "Sim. Descansar de problemas educacionais, escolares e problemas dos 'familiares' dos educandos que nos gastam tempo demasiado. Mas o baixo salário não deixa”.

Esses dados confirmam os de Folle e Nascimento (2009), demonstrando que o abandono da profissão representa uma ruptura com a atividade, traduzida em uma real renúncia (abandono definitivo) ou em um desejo intenso de desvinculação do ambiente de trabalho, mesmo que não concretizado por diversas razões, principalmente pela falta de alternativa profissional.

Os professores entrevistados na rede privada, por serem mais jovens e apresentarem menor tempo de carreira, relataram um menor anseio em se aposentar. Entretanto, a carga horária se mostrou um fator recorrente: "Não. Não me aposentaria, mas se pudesse reduzir minha carga horária, poderia desempenhar muito melhor meu trabalho".

Entre os docentes entrevistados no município de Viçosa, 36,62\% já pediram algum tipo de afastamento, sendo esse índice superior a $40 \%$ entre os profissionais que atuam na rede pública. Na rede privada, apenas $20 \%$ dos entrevistados já se ausentaram de suas atividades (Tabela 5).

Foram identificados casos de afastamentos devido a problemas psicológicos como ansiedade, depressão e estresse apenas entre os docentes da rede pública. Os professores que atuam no ensino privado se ausentaram apenas devido a problemas de saúde física. Esses dados corroboram os encontrados por Conti (2003), que afirma existirem outras formas de afastamento da docência, entre elas as saídas estratégicas, especialmente as viagens, a formação continuada e a licença-saúde.

A maioria dos pedidos de afastamento esteve relacionada a questões de saúde, sendo ela física ou psicológica (Tabela 6). Esses dados confirmam os de Lapo (1999) e Lima (2004), que destacam como fatores que mais contribuem para o afastamento dos professores as doenças respiratórias, os transtornos mentais e as doenças do sistema osteomuscular.

Os dados obtidos nessa pesquisa permitem inferir uma possível correlação entre as condições de trabalho e a saúde do professor. Assim, a insatisfação profissional e as condições inadequadas de trabalho podem vir a desencadear alterações no bem-estar físico ou psicológico desses profissionais, deixando-os mais propícios a desenvolverem o burnout e levando-os a se afastarem dos seus postos de trabalho. 
Tabela 5 - Número de professores que já pediram algum tipo de afastamento

\begin{tabular}{lrr|rr|cr}
\hline \multirow{2}{*}{ Afirmativa } & \multicolumn{2}{c}{$\begin{array}{c}\text { Escolas } \\
\text { Estaduais }\end{array}$} & \multicolumn{2}{c}{$\begin{array}{c}\text { Escolas } \\
\text { Municipais }\end{array}$} & \multicolumn{2}{c}{$\begin{array}{c}\text { Escolas } \\
\text { Particulares }\end{array}$} \\
\cline { 2 - 7 } & \multicolumn{1}{c}{ N. } & $\%$ & N. & \multicolumn{2}{c}{ N. } & \% \\
\hline Sim & 11 & 44,00 & 11 & 42,31 & 4 & 20,00 \\
Não & 14 & 56,00 & 15 & 57,69 & 16 & 80,00 \\
Total & $\mathbf{2 5}$ & $\mathbf{1 0 0 , 0 0}$ & $\mathbf{2 6}$ & $\mathbf{1 0 0 , 0 0}$ & $\mathbf{2 0}$ & $\mathbf{1 0 0 , 0 0}$ \\
\hline
\end{tabular}

Fonte: Banco de dados da pesquisa.

Elaboração dos autores.

Tabela 6 - Fatores que levaram os professores a pedir algum tipo de afastamento

\begin{tabular}{lcc|ccc|cc}
\hline \multirow{1}{*}{\multicolumn{1}{c}{ Categorias }} & \multicolumn{2}{c}{$\begin{array}{c}\text { Escolas } \\
\text { Estaduais }\end{array}$} & \multicolumn{2}{c}{$\begin{array}{c}\text { Escolas } \\
\text { Municipais }\end{array}$} & \multicolumn{2}{c}{$\begin{array}{c}\text { Escolas } \\
\text { Particulares }\end{array}$} \\
\cline { 2 - 8 } & N. & $\%$ & N. & $\%$ & N. & $\%$ \\
\hline Ansiedade & 0 & 0,00 & 1 & 3,85 & 0 & 0,00 \\
Cursar pós-graduação & 1 & 4,00 & 0 & 0,00 & 0 & 0,00 \\
Depressão & 1 & 4,00 & 1 & 3,85 & 0 & 0,00 \\
Descontrole menstrual & 1 & 4,00 & 0 & 0,00 & 0 & 0,00 \\
Estresse & 2 & 8,00 & 0 & 0,00 & 0 & 0,00 \\
Licença maternidade & 1 & 4,00 & 1 & 3,85 & 0 & 0,00 \\
Luto & 0 & 0,00 & 1 & 3,85 & 0 & 0,00 \\
Pressão alta & 1 & 4,00 & 0 & 0,00 & 0 & 0,00 \\
Problemas de saúde & 3 & 12,00 & 5 & 19,23 & 4 & 20,00 \\
Realização de cirurgias & 3 & 12,00 & 1 & 3,85 & 0 & 0,00 \\
Nunca pediram afastamento & 14 & 56,00 & 16 & 61,54 & 16 & 80,00 \\
\hline
\end{tabular}

Fonte: Banco de dados da pesquisa.

Elaboração dos autores.

Entre os docentes que já pediram algum tipo de afastamento, $42,31 \%$ afastaram-se uma única vez, e apenas 11,54\%, referente a profissionais que lecionam na rede estadual, já usufruíram desse direito mais de três vezes (Tabela 7). $\mathrm{O}$ baixo índice de afastamentos e a pequena frequência na qual eles ocorrem podem ser justificados pela idade e experiência dos entrevistados, visto que a maioria dos professores, principalmente da rede pública, possui mais de 40 anos $(54,93 \%)$ e está no cargo há mais de dez anos (53,52\%). Esses dados estão de acordo com Maslach (1982 apud Carlotto, 2002), cujo relato aponta que professores com mais idade parecem já ter desenvolvido a decisão de permanecer na carreira, demonstrando menos preocupação com os estressores ou com os sintomas pessoais relacionados ao estresse. Em contrapartida, professores jovens apresentam maior tendência em abandonar sua profissão como consequência do burnout.

Os resultados obtidos com professores que atuam no ensino privado indicam que esses profissionais estão mais satisfeitos com sua profissão, pois $80 \%$ dos 


\section{Tabela 7 - Número de pedidos de afastamento solicitados pelos docentes}

\begin{tabular}{|c|c|c|c|c|c|c|}
\hline \multirow[t]{2}{*}{ Categorias } & \multicolumn{2}{|c|}{$\begin{array}{l}\text { Escolas } \\
\text { Estaduais }\end{array}$} & \multicolumn{2}{|c|}{$\begin{array}{c}\text { Escolas } \\
\text { Municipais }\end{array}$} & \multicolumn{2}{|c|}{$\begin{array}{c}\text { Escolas } \\
\text { Particulares }\end{array}$} \\
\hline & N. & $\%$ & N. & $\%$ & $\mathrm{~N}$. & $\%$ \\
\hline Uma vez & 2 & 8,00 & 4 & 15,38 & 2 & 10,00 \\
\hline Duas vezes & 4 & 16,00 & 3 & 11,54 & 2 & 10,00 \\
\hline Três vezes & 2 & 8,00 & 1 & 3,85 & 0 & 0,00 \\
\hline Cinco vezes & 1 & 4,00 & 0 & 0,00 & 0 & 0,00 \\
\hline Seis vezes & 2 & 8,00 & 0 & 0,00 & 0 & 0,00 \\
\hline Nove vezes & 0 & 0,00 & 1 & 3,85 & 0 & 0,00 \\
\hline
\end{tabular}

Fonte: Banco de dados da pesquisa.

Elaboração dos autores.

docentes não manifestaram vontade em se aposentar, caso fosse possível, e 75\% afirmaram estar realizados profissionalmente, destacando como fatores o prazer pelo trabalho, a valorização profissional e pessoal. Apenas $20 \%$ dos docentes já se afastaram do cargo, devido a problemas de saúde como conjuntivite, problemas de coluna e fraturas, não sendo observados quadros de estresse, depressão e ansiedade, como no ensino público. Esse fato pode ser comprovado por meio das respostas de docentes que atuam em ambas as redes de ensino no município de Viçosa: "Faço o que gosto. Não me sinto valorizada e reconhecida financeiramente pelo poder público. Na escola particular que leciono, tenho um salário baseado no piso salarial do sindicato, por consequência, melhor do que na rede pública".

Por fim, os professores foram questionados sobre se atribuíam a seu trabalho algum tipo de doença que possuem ou que já possuíram. Cerca de $43 \%$ responderam positivamente, citando vários problemas como: dores no ombro, enxaqueca, depressão, estresse, insônia, lesão por esforço repetitivo (LER), entre outros. Como observado anteriormente, apenas $20 \%$ dos docentes da rede privada relataram apresentar algum problema de saúde e os relacionaram à profissão, sendo esses profissionais acometidos principalmente por problemas de ordem física (Tabela 8).

A maioria dos profissionais (51,32\%) afirmou não possuir ou não saber se apresentava algum tipo de problema de saúde que pudesse atribuir ao trabalho. Poucos desses docentes foram convictos ao fazer essa afirmativa, e grande parte deles não justificou ou relatou apresentar algum problema, porém não podiam afirmar que o fato estivesse relacionado à sua profissão (Tabela 8): "Não sei. Tenho enxaqueca, dores no estômago e hérnia de disco, mas não sei se posso relacioná-las ao trabalho".

Notou-se que esses profissionais não são acometidos por apenas um problema de saúde e que as condições de trabalho não são os principais fatores que desencadeiam esses problemas, mas sim o período de tempo no qual os profissionais estão expostos à situação de estresse: "Sim. Tenho enxaqueca, insônia, problemas de coluna. Acredito que de alguma forma elas estejam relacionadas ao excesso de aulas semanais (36 aulas)".

Segundo Reis et al. (2006), ensinar é uma atividade altamente estressante, com repercussões evidentes na saúde física, mental e no desempenho profissional dos professores. Entre as repercussões mais relatadas, destacam-se doenças 
Tabela 8 - Doenças que os docentes atribuem ao seu trabalho

\begin{tabular}{|c|c|c|c|c|c|c|c|c|}
\hline \multirow[t]{2}{*}{ Afirmativa } & \multirow{2}{*}{\multicolumn{2}{|c|}{ Categorias }} & \multicolumn{2}{|c|}{$\begin{array}{l}\text { Escolas } \\
\text { Estaduais }\end{array}$} & \multicolumn{2}{|c|}{$\begin{array}{c}\text { Escolas } \\
\text { Municipais }\end{array}$} & \multicolumn{2}{|c|}{$\begin{array}{c}\text { Escolas } \\
\text { Particulares }\end{array}$} \\
\hline & & & $\mathrm{N}$. & $\%$ & $\mathrm{~N}$. & $\%$ & $\mathrm{~N}$. & $\%$ \\
\hline \multirow{19}{*}{ Sim } & Ansiedade & & 0 & 0,00 & 2 & 7,69 & 0 & 0,00 \\
\hline & Colesterol & & 1 & 4,00 & 0 & 0,00 & 0 & 0,00 \\
\hline & Depressão & & 1 & 4,00 & 1 & 3,85 & 0 & 0,00 \\
\hline & Diabetes & & 0 & 0,00 & 1 & 3,85 & 0 & 0,00 \\
\hline & Dores na coluna & & 0 & 0,00 & 1 & 3,85 & 0 & 0,00 \\
\hline & Dores no ombro & & 2 & 8,00 & 0 & 0,00 & 1 & 5,00 \\
\hline & Enxaqueca & & 2 & 8,00 & 1 & 3,85 & 1 & 5,00 \\
\hline & Estresse & & 1 & 4,00 & 2 & 7,69 & 2 & 0,00 \\
\hline & Insônia & & 1 & 4,00 & 0 & 0,00 & 0 & 0,00 \\
\hline & Labirintite & & 0 & 0,00 & 1 & 3,85 & 0 & 0,00 \\
\hline & Lesão por esforço repetitivo (LER) & & 1 & 4,00 & 1 & 3,85 & 0 & 0,00 \\
\hline & Problemas de vista & & 0 & 0,00 & 0 & 0,00 & 2 & 10,00 \\
\hline & Problemas na tireoide & & 0 & 0,00 & 1 & 3,85 & 0 & 0,00 \\
\hline & Problemas nas cordas vocais & & 0 & 0,00 & 0 & 0,00 & 1 & 5,00 \\
\hline & Psoríase & & 1 & 4,00 & 0 & 0,00 & 0 & 0,00 \\
\hline & Tendinite & & 1 & 4,00 & 0 & 0,00 & 0 & 0,00 \\
\hline & Varizes/Dores nas pernas & & 1 & 4,00 & 2 & 7,69 & 0 & 0,00 \\
\hline & Ausência de justificativa & & 1 & 4,00 & 0 & 0,00 & 0 & 0,00 \\
\hline & & Total & 13 & 44,00 & 13 & 50,02 & 7 & 25,00 \\
\hline \multirow{3}{*}{ Não } & Não tem problemas de saúde & & 1 & 4,00 & 2 & 7,69 & 0 & 0,00 \\
\hline & Ausência de justificativa & & 14 & 56,00 & 11 & 42,30 & 11 & 55,00 \\
\hline & & Total & 15 & 60,00 & 13 & 49,99 & 11 & 55,00 \\
\hline \multirow[t]{2}{*}{ Não sei } & Ausência de justificativa & & 1 & 4,00 & 0 & 0,00 & 3 & 25,00 \\
\hline & & Total & 1 & 4,00 & $\mathbf{0}$ & 0,00 & 3 & 25,00 \\
\hline
\end{tabular}

Fonte: Banco de dados da pesquisa.

Elaboração dos autores.

cardiovasculares, problemas respiratórios, neuroses, fadiga, insônia, tensão nervosa, ansiedade, depressão, irritabilidade, hostilidade e exaustão emocional.

\section{CONSIDERAÇÕES FINAIS}

Os professores das redes de ensino do município de Viçosa demonstram várias vezes seu prazer pela profissão e acreditam em seu papel como agentes transformadores da sociedade. Porém, mesmo sendo explícito o sentimento de realização pessoal nesses profissionais, foi possível constatar, principalmente entre os docentes do ensino público, insatisfação com as condições de trabalho nas quais estão inseridos. Apesar dos contextos negativos, os professores não abandonam a profissão em virtude de razões como gosto pelo ensino e a expectativa por um futuro reconhecimento profissional.

Os dados obtidos nesta pesquisa permitem avaliar que o fator produtividade afeta de diferentes maneiras a satisfação dos docentes do ensino público e privado do 
município de Viçosa. O desinteresse dos alunos da rede pública, somado aos baixos salários, acarreta um sentimento de insatisfação dos docentes, que não veem seus esforços convertidos em aprendizado. Entretanto, na rede privada os docentes tendem a questionar o excesso de cobranças, mesmo em condições nas quais sua produtividade é adequada.

A questão salarial apresentou-se como fator desencadeador de vários problemas, sendo citada em grande parte nas respostas dos docentes entrevistados. Em virtude desse fator, principalmente os docentes do ensino público tendem a se dedicar a uma dupla ou tripla jornada de trabalho para obter uma melhor remuneração, apresentando pouco tempo para descansar e se dedicar à família. Mais comuns nesses profissionais são os sintomas de estresse, depressão e ansiedade, característicos da síndrome de burnout.

Com os dados obtidos, não foi possível quantificar se realmente os docentes do município de Viçosa apresentam a síndrome de burnout. Entretanto, ao comparar os dados presentes na literatura e o perfil dos profissionais entrevistados neste trabalho, percebe-se que os professores da rede pública de ensino se mostraram mais propensos a desenvolver o burnout que os professores da rede privada. A precariedade em termos de salário e condições de trabalho compõe um contexto no qual esses professores se expõem a uma intensa e estressante rotina, afetando a qualidade de seu trabalho e bem-estar mental. Os profissionais do ensino privado, por atuarem em escolas com melhor infraestrutura, maior disponibilidade de recursos didáticos e que oferecem uma melhor remuneração, estão menos propensos a desenvolver sentimentos de insatisfação em relação a sua atuação profissional e consequentemente o burnout.

\section{REFERÊNCIAS}

Amado, Elizabeth. O trabalho dos professores do ensino fundamental: uma abordagem ergonômica. 2000. Dissertação (Mestrado em Engenharia de Produção) - Universidade Federal de Santa Catarina, Florianópolis, 2000.

Bardin, Laurece. Análise de conteúdo. Lisboa: Edições 70, 1977.

Benevides-Pereira, Ana Maria Teresa (Org.). Burnout: quando o trabalho ameaça o bem-estar do trabalhador. São Paulo: Casa do Psicólogo, 2002.

Caldas, Andréa do Rócio. Desistência e resistência no trabalho docente: um estudo das professoras e professores do ensino fundamental da rede municipal de educação de Curitiba. 2007. Tese (Doutorado em Educação) - Universidade Federal do Paraná, Curitiba, 2007.

Carlotto, Mary Sancha. A síndrome de burnout e o trabalho docente. Psicologia em Estudo, Maringá: UEM, v. 7, n. 1, p. 21-29, jan./jun. 2002.

Sindrome de burnout em professores de instituiçóes particulares de ensino. 2005. Tese (Doutorado em Psicologia Social) - Universidade de Santiago de Compostela, Santiago de Compostela, Espanha, 2005.

CNTE - Confederação Nacional dos Trabalhadores em Educação. Retrato da escola II. Brasilia, DF: CNTE, 2001. Disponível em: <http://www.cnte.org.br/index.php/publica\% C3\%A7\%C3\%B5es/pesquisas/74-retrato-da-escola-2 >. Acesso em: 2 jun. 2012.

CoDo, Wanderley (Coord.). Educação, carinho e trabalho: burnout, a síndrome da desistência do educador, que pode levar à falência da educação. Petrópolis: Vozes, 1999. 
Conti, Celso Luiz Aparecido. Imagens da profissão docente: um estudo sobre professoras primárias em início de carreira. 2003. Tese (Doutorado em Educação) - UNICAMP, Campinas, 2003.

Cury, Augusto. Professor é um dos profissionais estressados do país. In: Pinotti, Sonia Aparecida Gonçalvez. Stress no professor: fontes, sintomas e estratégias de controle. Revista Uniara, Araraquara: Centro Universitário de Araraquara, n. 17/18, 2005/2006.

Fígoli, Moema, Gonçalvez Bueno. Evolução da educação no Brasil: uma análise das taxas entre 1970 e 2000, segundo o grau da última série concluída. Revista Brasileira de Estatística Populacional, São Paulo: ABEP, v. 23, n. 1, p. 129-150, jan./jun. 2006.

Folle, Alexandra; Nascimento,Juarez Vieira. Aderência à profissão educação física: estudo de casos no magistério público estadual de Santa Catarina. Revista da Educação Física/UEM, Maringá: UEM, v. 20, n. 3, p. 353-367, $3^{\circ}$ trim. 2009.

GARCIA, Ignacio M. Burnout en profesores y marginación social: diferencias en una muestra de profesores de centros educativos marginado y no marginados. In: Congreso NacionaL de Psicología Social, 3., 1990, Santiago de Compostela.Anais... Santiago de Compostela, Tórculo A. G.

Gatti, Bernardete Angelina. Os professores e suas identidades: o desvelamento da heterogeneidade. Cadernos de Pesquisa, São Paulo: Fundação Carlos Chagas, n. 98 , p. 85-90, ago. 1996.

KulLoK, Maisa Gomes Brandão. A formação docente para a inclusão escolar de alunos especiais. In: Seminário de Pesquisa do NUPEPE, 2., 2010, Uberlândia. Anais... Uberlândia: Escola de Educação Básica da Universidade Federal de Uberlândia, 2010. p. 44-50.

LAPo, Flavinês Rebolo. Professores retirantes: um estudo sobre a evasão de professores do magistério público do estado de São Paulo (1990-1995). 1999. Dissertação (Mestrado em Educação) - Universidade de São Paulo, São Paulo, 1999.

Lengert, Rainer. O início da carreira docente: um estudo de representações sociais. 2005. Dissertação (Mestrado em Teologia) - Escola Superior de Teologia, São Leopoldo, 2005.

Levy, Gisele Cristine Tenório de Machado. Avaliar o indice de burnout em professores da rede pública de ensino localizada na região Sudeste. 2006. Dissertação (Mestrado em Educação) Universidade Estadual do Rio de Janeiro, Rio de Janeiro, 2006.

Lima, Emília Freitas. Construção do início da carreira: reflexões a partir de pesquisas brasileiras. Educação, Santa Maria: UFSM, v. 29, n. 2, p. 85-98, 2004.

Maslach, Christina. Burnout: the cost of caring. Englewood Cliffs, NJ: Prentice-Hall,1982. . Schaufeli, Wilmar B.; Leiter, Michael P.Job burnout.Annual Review Psychology, n. 52, p. 397-422, 2001.

Meleiro, Alexandrina Maria Augusta da Silva. O stress do professor. In: Lipp, Marilda (Org.). O stress do professor. São Paulo: Papirus, 2000.v. 1, p. 11-27.

Moreno-Jimenez,Bernardo; Garrosa-Hernandez,Eva; Gálvez,Macarena; GonzÁlez, José Luis; Benevides-Pereira, Ana Maria Teresa. A avaliação do burnout em professores. Comparação de instrumentos: CBP-R e MBI-ED. Psicologia em Estudo, Maringá: UEM, v. 7, n. 1, p. 11-19, jan./jun. 2002. 
NAujorks, Maria Inês. Stress e inclusão:indicadores de stress em professores frente à inclusão de alunos com necessidades educacionais especiais. Cadernos de Educação Especial, Santa Maria:UESM,v.1,n.20,2002.Disponível em: <http://coralx.ufsm.br/revce/ceesp/2002/02/ a9.htm>. Acesso em: 2 set. 2014.

Pinotti, Sonia Aparecida Gonçalvez. Stress no professor: fontes, sintomas e estratégias de controle. Revista Uniara, Araraquara: Centro Universitário de Araraquara, n. 17/18, p. 207-216, 2005/2006.

Ramos, Susana Isabel Vicent. Grau de satisfação docente dos estagiários de ciências do desporto e educação física. Psicologia.pt - O Portal dos Psicólogos. 2008. Disponível em: $<$ http://www.psicologia.pt/artigos/ver_artigo.php?codigo=A0425\&area=d6>. Acesso em: 1 jun. 2012.

Reinhold, Helga Hinkenickel. O burnout. In: Lipp, Marilda (Org.). O stress do professor. 5. ed. Campinas: Papirus, 2001. p. 63-80.

Reis, Eduardo José Farias Borges; Araújo, Tania Maria de; Carvalho, Fernando Martins; Barbalho, Leonardo; Silva, Manuela Oliveira e. Docência e exaustão emocional. Educação E Sociedade, Campinas: CEDES, v. 27, n. 94, p. 229-253, jan./abr. 2006.

Rocha, Décio; Deusdará, Bruno. Análise de conteúdo e análise do discurso: aproximações e afastamentos na (re)construção de uma trajetória. Alea, Rio de Janeiro: UFRJ, v. 7, n. 2, p. 305-322, jul./dez. 2005.

Sampson, Jane. Stress survey of clinical psychologists in Scotland. In: Benevides-Pereira, Ana Maria Teresa (Org.). Burnout quando o trabalho ameaça o bem-estar do trabalhador. São Paulo: Casa do Psicólogo, 2002.

Silva, Joilson Pereira; Damásio, Bruno Figueiredo; Melo, Suéllen Alencar; Aquino, Thiago Antônio Avelar de. Estresse e burnout em professores. Revista Fórum Identidades, Itabaiana: UFS, ano 2, v. 3, p. 75-83, jan./jun. 2008.

\section{SOBRE OS AUTORES}

Alberto Abrantes Esteves-Ferreira é mestrando em fisiologia vegetal pela Universidade Federal de Viçosa (UFV).

E-mail: alberto.esteves@ufv.br

Douglas Elias Santos é mestrando em biologia celular e estrutural pela Universidade Federal de Viçosa (UFV).

E-mail: douglas.santos@ufv.br

Rafael Gustavo Rigolon é professor da Universidade Federal de Viçosa (UFV) e doutorando em educação para as ciências pela Universidade Estadual de São Paulo (UNESP).

E-mail: rafael.rigolon@ufv.br

Recebido em março de 2013

Aprovado em setembro de 2013 